\title{
Percepções sobre a Ponte Rio Negro: uma constelação de olhares
}

\section{Perceptions about the Black River Bridge: a constellation of perspectives}

Hamida Assunção Pinheiro - doutoranda em Ciências do Ambiente e Sustentabilidade na Amazônia; professora do Departamento de Serviço Social da Universidade Federal do Amazonas (UFAM)/ Brasil-Amazonas-Manaus. E-mail: hamida.assuncao@gmail.com

Antonio Carlos Witkoski - doutor em Ciências Sociais; professor do Programa de Pós-Graduação em Ciências do Ambiente e Sustentabilidade na Amazônia na Universidade Federal do Amazonas (UFAM)/Brasil-Amazonas-Manaus. E-mail: acwitkoski@uol.com.br

\section{Resumo}

$\mathrm{O}$ artigo apresenta e discute as múltiplas visões acerca da construção da Ponte Rio Negro. Esta obra, inaugurada em 24 de outubro de 2011, interligou a cidade de Manaus ao município do Iranduba. Para além de uma grandiosa edificação arquitetônica, a ponte trouxe mudanças nas configurações de espaço, lugar e tempo, principalmente para os moradores de Manaus e dos municípios que se localizam em suas proximidades.

\begin{abstract}
The article introduces and discusses the different visions about the construction of the Rio Negro Bridge. This bridge, inaugurated in 24 of October of 2011, intertwined the city of Manaus in the Iranduba. In addition to a magnificent architectural building, the bridge has brought changes in the configuration of space, place and time, mainly for the residents of Manaus and that are located in its nearby.
\end{abstract}

\section{Palavras-chave}

Ponte Rio Negro. Percepção ambiental. Espaço. Lugar. Tempo.

\section{Keywords}

Rio Negro Bridge. Environmental perception. Space. Place. Time. 


\section{INTRODUÇÃO}

Em tempos de grandes ameaças sociais e ambientais, faz-se necessário refletir acerca do modo pelo qual o homem compreende e se relaciona com o ambiente. Sabe-se que, desde 1968, ano marcado pela criação do Clube de Roma, a questão ambiental vem sendo colocada como um problema mundial que ameaça a continuidade da vida humana no Planeta Terra. Nos anos subsequentes ao Clube de Roma ocorreram encontros, conferências, convenções e protocolos que revelam um pouco do aumento das preocupações em torno da proteção do ambiente: Conferência das Nações Unidas sobre Meio Ambiente Humano, realizada em Estocolmo-Suécia em 1972; Conferência das Nações Unidas sobre Meio Ambiente e Desenvolvimento, realizada no Rio de Janeiro, Brasil, em 1992; Cúpula Mundial sobre Desenvolvimento Sustentável, realizada em Johanesburgo, África do Sul, em 2002; Conferência das Nações Unidas sobre o Desenvolvimento Sustentável, realizada no Rio de Janeiro, Brasil, em 2012, dentre outros.

$\mathrm{Na}$ contemporaneidade, os frutos destas discussões têm resultados ainda bastante modestos, em comparação aos produtos das ações humanas que degradam o ambiente. A relação homem-natureza no capitalismo é cingida pela superexploração dos recursos naturais e humanos, o que tem tido consequências bem graves para a sociedade e para o ambiente. Índices de pobreza jamais vistos anteriormente, extinção de muitas espécies animais e vegetais, poluição, escassez de água e aquecimento da Terra, são apenas alguns dos problemas que desafiam a sociedade contemporânea. Nesse cenário, não se pode ignorar que as ações humanas se colocam como os principais agentes de destruição do ambiente, entretanto, é preciso acreditar que os homens também possuem a capacidade intelectual de poder rever tais ações e trabalharem numa perspectiva mais ecológica e socialmente mais justa.

Este texto tem como objetivo discutir a relação homem e ambiente na contemporaneidade, tomando como ponto de referência a Amazônia e, mais especificamente, a realidade de Manaus e do município de Iranduba. As reflexões e análises giram em torno das convergências e divergências dos sujeitos em torno da construção da Ponte Rio Negro, que desde 2011 interligou a capital do estado do Amazonas ao município de Iranduba. O artigo examina as diferentes percepções acerca da Ponte Rio Negro, a partir das notícias veiculadas em um dos jornais de maior circulação na cidade de Manaus e do resultado de pesquisa já realizada junto aos moradores de Iranduba antes da construção da Ponte. Foi construído a partir de pesquisa documental e bibliográfica, com foco nas

Novos Cadernos NAEA, v. 16, n. 1, Suplemento, p. 69-87, jun. 2013 
percepções ambientais dos envolvidos: moradores, políticos, trabalhadores e outros.

A construção da Ponte Rio Negro foi um acontecimento histórico importante, que chamou a atenção pela arquitetura, pelos custos financeiros e pelos impactos sociais e ambientais decorrentes. Significou mudanças nos modos de vida de muitos moradores dos arredores e deslocamento dos trabalhadores envolvidos no sistema de balsas que operava anteriormente nos portos, e de outros que tinham atividades formais e informais nas localidades diretamente envolvidas.

\section{ACERTANDO AS ARESTAS: A RELAÇÃO HOMEM/AMBIENTE E A PERCEPÇÃO AMBIENTAL}

A relação homem e ambiente é a base da vida em sociedade. $\mathrm{O}$ homem vive no e com o ambiente, interagindo incessantemente com recursos existentes para a manutenção e reprodução da vida. Dessa forma, como bem afirma Reigota (2010), o ambiente deve ser compreendido como espaço de troca entre elementos naturais e sociais, trocas estas que possibilitam mudanças tanto no meio natural, quanto no meio social. Assim, homem e ambiente se transformam e são transformados mutuamente numa relação dinâmica.

A interação entre homem e ambiente também deve ser entendida como elemento-chave para a noção de percepção ambiental. A percepção acerca do ambiente sofre influência das afinidades e das particularidades do ser humano; por isso, pode ser diferente para cada indivíduo. A percepção do ambiente pelo homem é o que impulsiona ou cerceia o agir. Nesse sentido, Gunther (2011) destaca que o ambiente não só reage como estimula o homem a agir. O ambiente não é passivo - ele apresenta possibilidades funcionais para os homens.

O autor destaca dois conceitos importantes para a compreensão do modo como funciona a estimulação realizada pelo ambiente sobre o homem. São eles: a valência e a affordance. A valência é uma noção recuperada da teoria de campo de Kurt Lewis. Ela é usada para designar o valor subjetivo que o ambiente pode assumir para o homem, de acordo com sua funcionalidade. A valência pode ser positiva ou negativa, ou seja, atrair ou repelir a atenção e ação humana.

Já a Affordance é um termo cunhado por James J. Gibson para se referir à capacidade física e objetiva, bem como subjetiva e psicológica que o ambiente apresenta ao homem. Essas capacidades são percebidas visualmente pelo homem e o convidam à ação. Apesar de também ser uma capacidade física, ela não 
pertence nem ao sujeito e nem ao objeto, mas é própria da relação de interação entre eles. Gunther (2011) salienta que um único ambiente pode ter distintas affordances para animais diferentes, mesmo sendo da mesma espécie.

Ambos os conceitos são importantes para a compreensão da noção de percepção ambiental. Eles reforçam a ideia de que o ambiente não é estático e encontra-se em constante mudanças, assim como o homem. A relação homem e ambiente é marcada pela reciprocidade dinâmica. Homem e ambiente são partes de um todo. Não estão isolados, ao contrário, são complementares. A percepção ambiental é um complexo resultante dessa interação entre homem e ambiente, e envolve além do que é possível assimilar pela visão. Ela é mais ampla e mais profunda, capta sensações, aromas, expetativas, valores, afetividades, comportamentos etc.

Segundo Campos-de-Carvalho, Cavalcante e Nóbrega (2011), o ambiente é um conceito multidimensional, que apresenta tanto características naturais, quanto construídas. Além das características físicas, o ambiente possui componentes não físicos (crenças, motivações etc.) e aspectos sociais, culturais, econômicos e políticos. O significado de ambiente vai além do que é perceptível aos olhos.

O ambiente é um assunto discutido em diferentes áreas do conhecimento. O termo envolve consensos e dissensos, traz à tona discussões polêmicas acerca da degradação e do esgotamento dos recursos naturais. Não se trata de assunto exclusivo a nenhuma área do saber e, cada vez mais, as questões ambientais se colocam como preocupação de todos, ainda que em diferentes perspectivas.

Fischer (1994) considera que o ambiente é, na atualidade, uma temática que está na moda, mas é um assunto que vem sendo discutido há muitas décadas. Nas palavras do autor, "o ambiente é essencialmente o espaço organizado nas nossas sociedades; ele constitui o quadro social em que vivemos. Neste sentido, já não podemos dissociar características físicas e dimensões sociais de um lugar"' (FISCHER, 1994, p.10). Na abordagem psicossocial, o ambiente é compreendido como 'mundo em nossa volta' ou 'ambiente das nossas condutas', por isso deve ser entendido também como produto das intervenções sociais e culturais.

Kuhnen (2011) assinala que o mundo, apesar de ser um só, é visto por vários e diversificados sujeitos. Para o autor, [...] "Os homens percebem o mundo pelo corpo e a partir do corpo na vivência de experiências cotidianas" (HIGUCHI apud KUHNEN, 2011, p. 259). E, para exteriorizar suas percepções, os homens necessitam representar. Por isso, a autora enfatiza que os indivíduos percebem representando, ou seja, através da fala, do pensamento, da elaboração de desenhos, de textos e também da expressão corporal.

Novos Cadernos NAEA, v. 16, n. 1, Suplemento, p. 69-87, jun. 2013 
Como produto da interação entre homem e ambiente, a percepção ambiental também dá origem a imagens e significados. Segundo Kuhnen (2011), as imagens são criadas a partir das sensações imediatas no ato da experiência e também podem ser decorrentes das lembranças já vividas. Essas imagens são decodificadas pela mente humana, conforme valores e princípios socioculturais, e dão origem aos significados. Desse modo, pode-se afirmar que não há ambiente físico destituído das dimensões sociais, culturais, políticas, espirituais e outras. $\mathrm{O}$ ambiente sempre é uma interpretação, fruto da cognição humana.

Higuchi, Kuhnen e Bomfim (2011) consideram a percepção ambiental como mediadora da cognição. A cognição ambiental é considerada um processo psicológico superior, que se difere em cada fase de vida do ser humano; e a dimensão temporal e espacial são elementos essenciais para a construção cognitiva. Espaço (lugar) e tempo são eixos norteadores da percepção e da cognição ambiental.

\section{ESPAÇO, LUGAR E TEMPO SOB A ÓTICA AMBIENTAL}

É importante esclarecer que espaço, lugar e tempo são importantes categorias analíticas. Segundo Cavalcante e Nóbrega, para uma compreensão mais refinada da relação homem e ambiente é imprescindível realizar inicialmente a distinção entre as noções de espaço e de lugar. O espaço condiz àquilo que é exterior ao indivíduo, à configuração física, concreta, daquilo que está em volta do homem. Nas palavras das autoras, "o espaço é um todo que comporta qualquer coisa e qualquer ser” (CAVALCANTE; NÓBREGA, 2011, p.183).

A respeito da definição de lugar, as mesmas autoras reiteram o pensamento de Bachelard (1958) e confirmam que é a relação intensa do homem com o ambiente que possibilita a transformação do espaço em lugar. Essa transformação ocorre porque é durante a vivência que o homem atribui valores, sentimentos e significados ao ambiente. Por isso, Bachelard considera que o "espaço habitado transcende o espaço geométrico" (BACHELARD apud CAVALCANTE; NÓBREGA, 2011, p. 185). Sendo assim, lugar é o ambiente com o qual o homem mantém uma ligação marcada por afeto, valores ou sentimentos.

Vale tomar aqui uma visão mais clássica da psicologia ambiental e recorrer a Fischer (1994), que também distingue espaço e lugar. Em seu entendimento, o espaço não é algo independente, fechado e fixo; é um campo dinâmico, que só existe por intermédio da relação homem e ambiente. $\mathrm{O}$ autor chama a atenção para a influência e o condicionamento que o ambiente pode trazer para a vida

Novos Cadernos NAEA, v. 16, n. 1, Suplemento Especial, p. 69-87, jun. 2013 
humana, visto que as alterações (construções, destruição ou mudança) afetam diretamente o comportamento do homem.

Quanto ao conceito de lugar, Fischer (1994) expõe que são as experiências do homem no ambiente as responsáveis pelo estabelecimento de laços de afeto e desafeto. Para ele, o lugar é o "espaço vivido, ou seja, investido por uma experiência sensori-motora, táctil, visual, afectiva e social, que produz, através das relações estabelecidas com ele, um conjunto de significações carregadas de valores culturais próprios" (FISCHER, 1994, p. 38).

Este autor destaca em suas análises três tipos de lugares como fundamentais para a compressão da relação homem e ambiente. São eles: o ambiente residencial, o ambiente do trabalho e o ambiente institucional. São lugares distintos, mas que se interconectam no cotidiano do homem e preenchem parte significativa da vida humana. De modo geral, a vida humana acontece nesses ambientes, os quais se tornam lugar na medida em que ganham significados.

Espaço, lugar e tempo são categorias que necessariamente dialogam com a noção de ambiente. Todo ambiente está situado no espaço (que também pode ser lugar) e no tempo. Para Tuan (1983), espaço e lugar são componentes básicos do mundo vivido, lócus de experiências múltiplas e diversificadas. Para a construção da vida, o homem necessita tanto do espaço como do lugar, afirma o autor. Ele argumenta que estas noções não podem ser definidas uma sem a outra. O espaço é mais abstrato que o lugar, mas, à medida que se conhece melhor o espaço, este pode ir se tornado lugar. O lugar é segurança, enquanto que o espaço simboliza liberdade. Os homens estão ligados ao primeiro, mas desejam o segundo. O tempo está sempre presente na estruturação da vida, ainda que em alguns momentos não se tenha consciência dele.

Historicamente, os homens organizam-se em sociedade e apreciam a vida em grupo. A vida em grupo acontece situada no tempo e no ambiente, que pode se constituir enquanto espaço e/ou lugar. O espaço é uma necessidade biológica fundamental de todos os animais, sendo que, para os seres humanos é também um atributo psicológico, social e espiritual (TUAN, 1983).

Tuan (1983) nos diz que as pessoas são seres sociais e gostam da companhia de outros organismos da mesma espécie e de outras também. Aproximações e vivências entre seres humanos são compartilhadas em várias culturas, de modo e intensidade também diversos. Por isso, o autor assinala que espaço, lugar e tempo são recursos de apreciação cultural, ou seja, apresentam forte influência dos condicionantes peculiares a uma dada cultura.

No mundo ocidental, espaço é um símbolo comum de liberdade. O espaço é aberto, indica para o futuro e convida para a ação. Por outro lado,

Novos Cadernos NAEA, v. 16, n. 1, Suplemento, p. 69-87, jun. 2013 
o espaço também, pela sua amplitude, oferece ameaças e deixa o homem vulnerável, suscetível ao perigo. O lugar é um espaço mais fechado, íntimo e mais humanizado, que possui uma referência de valores e de sentimentos estabelecidos. Nas palavras de Tuan, [...] "o lugar é um mundo de significado organizado. É essencialmente um conceito estático. Se víssemos o mundo como processo em constante mudança, não seríamos capazes de desenvolver nenhum sentido de lugar" (TUAN, 1983, p.198).

As noções de espaço e tempo sofrem influência da cultura de cada lugar. Tuan (1983) exemplifica que, no oriente, para um morador das regiões onde se produz arroz, as noções de espaço e lugar podem ser bem diferentes daquelas de quem mora em outros ambientes com características distintas. Essa região é composta por áreas densamente povoadas e, para quem é nascido e criado no oriente, o ambiente possui algumas particularidade que podem ser evidenciadas na fala de um psiquiatra ambientalista chamado Aristide Esser, oriundo da ilha de Java. Referindo-se a sua terra natal, que chega a ter uma média de 400 habitantes por quilômetros quadrados, ele afirma se sentir em casa (sensação de lugar) e não se incomoda com o quantitativo de gente que habita uma mesma área. Já quando morou na Holanda para realizar seus estudos, sentia-se muito incomodado em ambientes maiores e bem menos povoado. Sobre o seu local de nascimento, ele afirma que [...] "a beleza de sua paisagem e sua gente tranquila e compreensiva produziram em mim imagens de liberdade em um mundo onde tudo é bonito. Ao contrário, a Holanda pareceuridiculamente pequena e opressiva" (ESSER apud TUAN, 1983, p. 70).

Estes argumentos tornam explícita a influência da cultura sobre as concepções de espaço e lugar. A percepção de lugar de Esser possui especificidades que advêm do ambiente onde vivenciou toda sua infância e juventude. Ele não se sente sufocado em um lugar pequeno (comparado à Holanda) e tão cheio de gente. Ao contrário, exprime bons sentimentos ao se referir a sua terra natal.

A questão do poder é outro fator que deve ser analisado - considera Tuan (1983). O espaço é mundialmente reconhecido como símbolo do poder e do prestígio. Tradicionalmente, os homens ou as nações mais fortes ocupam espaços maiores e, por isso, reforçam o domínio sobre os mais fracos. Nestas relações de poder, ganham força os conceitos auxiliares de espaciosidade e seu antônimo, que é o apinhamento. Ambos estão relacionados não apenas ao tamanho dos espaços, mas também à quantidade de pessoas e às formas de perceber o ambiente. A espaciosidade se referencia na sensação de estar livre. Esta sensação não depende apenas da área geométrica do espaço, mas de uma série de outros condicionantes, dentre os quais se destacam os psicossociais e os culturais.

Novos Cadernos NAEA, v. 16, n. 1, Suplemento Especial, p. 69-87, jun. 2013 
O apinhamento é a sensação de diminuição dos espaços e ameaça da liberdade, que é gerada pela presença de outras pessoas. $\mathrm{O}$ apinhamento também não depende apenas do tamanho físico do espaço. Tuan (1983) exemplifica o apinhamento com o caso do pianista tímido que toca sem observadores. Se uma única pessoa entrar para observá-lo, ele se sentirá acuado, mesmo que a sala seja grande o suficiente. No entanto, ele não se sentiria ameaçado por outros animais ou ainda por seres inanimados que estivessem no mesmo espaço. Outro exemplo explicitado pelo autor baseia-se na habilidade que os seres humanos possuem de tratar outros seres humanos como objetos, e não se sentirem apinhados diante de muitos homens, quando os considera como coisas. Um homem rico, por exemplo, cercado de criados, não se sente apinhado, visto que os criados são "invisíveis", devido ao baixo status social, explica o autor.

Conforme Tuan (1983), é preciso ainda compreender que há uma subjetividade implícita na interpretação de cada ambiente, além da questão cultural. Nesta medida, pondera que "no espaço aberto, uma pessoa pode chegar a ter um sentido profundo de lugar, e na solidão de um local protegido a vastidão do espaço exterior adquire uma presença obsessiva" (TUAN, 1983, p. 61). Esta subjetividade torna arriscada qualquer generalização sobre as noções de espaço e lugar, visto que provém da percepção ambiental, e esta, por sua vez, tem particularidades individuais.

Tuan (1983) acredita que o tempo está implícito no espaço e no lugar. Para o autor, o espaço indica movimento, enquanto o lugar significa pausa. A própria transformação do espaço em lugar necessita do tempo de vivência, mesmo que a quantidade de tempo decorrido não seja a única determinante para que isso ocorra. Quanto mais tempo convivemos em determinado ambiente, mais o conhecemos e criamos afeição e/ou desafeição. Todavia, é possível que, mesmo conhecendo bastante um dado ambiente, não seja desenvolvida qualquer afetividade pelo mesmo. O homem pode conviver grande parte de sua vida no mesmo ambiente e não reconhecê-lo como lugar. Por outro lado, o ser humano pode desenvolver uma paixão por um ambiente sem tê-lo conhecido fisicamente, mas apenas através de livros, fotografias, histórias etc.

O autor destaca que o tempo pode afetar a sensação de lugar, na medida em que a quantidade de tempo e a intensidade das experiências são decisivas para a configuração de lugar. A este respeito, Tuan (1983) faz um alerta, destacando que uma experiência rápida, porém intensa, é capaz de anular um longo passado.

Para os humanos o tempo é vivido por etapas: criança, jovem, adulto e velho. Em cada etapa de vida o homem percebe o tempo e o ambiente de modos diferentes. A criança não apresenta a mesma percepção, por possuir formas 
distintas de conhecer o ambiente. Tuan (1983) explica que a criança não percebe a fluidez do tempo, já para o adulto o tempo corre depressa. Por outro lado, a criança usa muito mais os sentidos para perceber o ambiente que o adulto. Não se trata apenas de uma diferença nas capacidades sensórias e mentais entre a criança e o adulto, mas de sensibilidade e de noção temporal (passado, presente e futuro).

Ainda no intuito de clarear o entendimento da relação homem e ambiente, Tuan (1983) fala da capacidade que os seres humanos possuem de se adaptar às situações postas, ainda que as mesmas sejam desfavoráveis. A adaptabilidade humana pode ser visualizada em diferentes realidades. Na região amazônica, por exemplo, temos uma infinidade de demonstrações, que vão desde a construção de flutuantes dentro dos rios e igarapés para servirem de moradia, até mesmo a criação de gado e outros animais em marombas. Essa capacidade de adaptação pode ocorrer tanto em ambientes naturais, como em ambientes construídos. A ponte sobre o Rio Negro, objeto de discussão neste artigo, é um exemplo de como a construção (artificial) pode modificar o ambiente (espaço e lugar) e a dinâmica da vida das pessoas envolvidas.

\section{A PONTE RIO NEGRO: UMA INTERSEÇÃO DE OLHARES}

É importante lembrar que a construção do espaço urbano na Amazônia ocorreu atrelada aos fluxos de desenvolvimento econômico, sobretudo no fim do século XIX e início do XX, quando Manaus viveu o período áureo da economia da borracha. Nesse momento, a cidade recebeu uma infraestrutura moderna para a época, caracterizada pela abertura de ruas, aterros de igarapés, pela construção de pontes, pela edificação de casas de alvenaria, pela implantação dos bondes, do sistema de energia, de telefonia etc. A modernização/urbanização da cidade de Manaus ocorreu de modo a contemplar áreas bastante restritas, situadas apenas no Centro da cidade, criando fronteiras espaciais marcadas pela exclusão, entre outras problemáticas sociais na cidade de Manaus e nos municípios vizinhos.

Sendo a percepção ambiental a forma pela qual o homem vivencia, compreende e representa o ambiente, as notícias de jornais e as falas dos moradores aqui analisadas revelam as mais diversificadas percepções acerca da Ponte Rio Negro. As falas de moradores do entorno, comerciantes, prefeitos, deputados e outros cidadãos mostram um emaranhado de opiniões e posicionamentos, alguns convergentes e outros bastante divergentes. A ideia de construção da ponte era ventilada desde a década de 1970, entretanto, sempre foi assunto polêmico, marcado por opiniões antagônicas.

Novos Cadernos NAEA, v. 16, n. 1, Suplemento Especial, p. 69-87, jun. 2013 
A ponte sobre o Rio Negro foi inaugurada no dia 24 de outubro de 2011, após três anos de obras, no dia em que a cidade de Manaus completou 342 anos. É a primeira ponte suspensa por cabos (estaiada) construída sobre um rio na Amazônia. Possui 3.595 metros e custou R\$ 1,099 bilhão de reais. Esta obra figurou por muito tempo como sonho, como algo que possibilitaria a resolução de uma gama de problemas socioeconômicos dos municípios e até mesmo da capital do estado. A ponte foi idealizada por vários grupos sociais, ainda que não fosse um anseio unânime.

$\mathrm{Na}$ ocasião da inauguração da ponte, em entrevista concedida ao jornal A crítica, o ex-governador do Amazonas e atual senador pelo estado, Sr. Eduardo Braga, afirmou que a ponte é "um sonho realizado, com certeza. [É] mais um sonho que está se realizando para todos os amazonenses". Na matéria intitulada Sonho realizado - Ponte é apenas o começo do futuro, o político destaca que o projeto de construção da ponte recebeu muitas críticas negativas, o que contribuiu para aumentar o nível de dificuldade de sua implantação. Ressalta, ainda, que o apoio do ex-presidente da república Luiz Inácio Lula da Silva, da presidenta Dilma Rousseff e do governador do Amazonas, Omar Aziz, foram fundamentais para a materialização da ponte.

Outra fala interessante veiculada pelo jornal A crítica, na ocasião da inauguração da ponte sobre o Rio Negro, é do deputado Francisco Souza. O parlamentar rememora que no dia 18 de junho de 2003 teve a ideia de propor um projeto à Assembleia Legislativa do Estado do Amazonas para a construção de uma ponte que interligasse Manaus ao interior do estado. Ele afirmou, ainda, que antes disso havia participado de uma reunião com os representantes do Conselho dos Cidadãos do município de Iranduba. O Deputado relembra que

[...] a ideia surgiu do pronunciamento do engenheiro Noronha, que representou os moradores do município de Iranduba. Ele aconselhou que a solução para o problema da travessia seria a construção de uma ponte. Ele mesmo havia trabalhado na construção da ponte Rio-Niterói e indicava essa solução para Manaus (A CRÍTICA, 2011, p. A10).

O deputado explica que, após a apresentação da proposta, o passo seguinte foi o recolhimento de 120 mil assinaturas no Porto do São Raimundo, o que durou uma média de seis meses. Em 5 de dezembro de 2005, lembra que foi marcada uma nova audiência pública:

[...] essa audiência pública foi para discutir o projeto, nessa altura, com o secretário de obras, o doutor Orlando Matos. Ele disse que o governo do estado já tinha seis estudos sobre o assunto e um novo percurso saindo da Vila Marinho para o Pepeta. Aí já tínhamos um fato novo que provou que o estado também vinha trabalhando nos estudos da ponte (A CRÍTICA, 2011, p. A10).

Novos Cadernos NAEA, v. 16, n. 1, Suplemento, p. 69-87, jun. 2013 
Estas observações expostas pelo deputado evidenciam um pouco das articulações políticas e populares que antecederam o início da construção. O projeto precisou ser amadurecido e discutido, o que levou alguns anos até o início da obra, que se deu em junho de 2008. O deputado destaca, ainda, que o próximo passo após a inauguração da Ponte Rio Negro é construir a ponte sobre o Rio Solimões:

Já existe uma luta para conquistar esse objetivo. Coletamos 48 mil assinaturas e desejo recolher 100 mil até o final de dezembro [2011], solicitando a construção da ponte do rio Solimões. No dia 27 de maio [2011] o próprio Henrique Levy iniciou os estudos para identificar o local mais viável para a construção da ponte (A CRÍTICA, 2011, p. A10).

Pinheiro (2011) salienta que a ideia de interligar o município de Iranduba à capital do estado existe há mais de 30 anos. Em pesquisa de campo realizada pela autora no Cacau Pirêra, distrito do Iranduba, antes da construção da Ponte foi identificado que a opção pela mesma não era um anseio homogêneo entre os moradores do distrito. Muitos moradores, ao invés de uma ponte, tinham preferência por um porto flutuante que acompanhasse a enchente, a cheia, a vazante e a seca do rio Negro. A autora expõe a fala de uma moradora do Cacau Pirêra a este respeito:

Então antigamente só se falava em porto, e agora já estão com negócio de ponte. Eu não vejo muita necessidade de botar uma ponte aqui não. Os ladrões vão ver uma pontezinha, aí eles fazem o roubo aqui e vão embora. A não ser que tenha uma fiscalização muito grande. Todo progresso tem a coisa boa e a coisa ruim (Maria do Socorro, comunicação pessoal).

A fala da entrevistada foi registrada em período anterior à abertura da ponte e mostra um certo desconforto em saber que seu local de moradia ficará ligado à capital do estado, que apresenta maiores índices de violência e de criminalidade. Outra moradora entrevistada pela autora tem opinião semelhante, e afirma que: "Nós aqui do Cacau Pirêra gostaríamos mesmo era de um porto definitivo, que não precisasse se mudar na seca. O Alfredo, ministro dos transportes, já teve aqui visitando e se comprometeu numa parceria com o governo de fazer o porto" (Maria Madalena, comunicação pessoal).

As falas das moradoras trazem elementos que merecem ser analisados. Um deles é a proximidade da cidade e, com isso, a chegada da violência, que antigamente estava restrita aos grandes centros urbanos. O roubo é o tipo de crime que ganha relevo na fala da primeira entrevistada. Ainda no discurso da primeira moradora, é notório que a construção da ponte sobre o Rio Negro é vista como progresso, mas que pode trazer vantagens e desvantagens. Talvez por isso, ambas tenham deixado muito clara a opção pelo porto. $\mathrm{Na}$ percepção da

Novos Cadernos NAEA, v. 16, n. 1, Suplemento Especial, p. 69-87, jun. 2013 
segunda entrevistada, o porto definitivo aparece não só como uma opção pessoal, mas que reflete a preferência de um grupo de moradores. Quando a moradora afirma - "nós", está implícito que ela conhece outras pessoas que compartilham da mesma opinião. Além disso, o depoimento revela que a moradora está atenta às articulações políticas em torno da situação.

É interessante refletir acerca da riqueza destas falas e analisar suas entrelinhas. A preferência pelo porto, em detrimento da ponte, pode significar uma tentativa de preservação do estilo de vida dos moradores. O gosto pela vida ligada aos movimentos das águas do rio Negro se revela na verbalização das referidas moradoras, quando elas mencionam que seria importante um porto que acompanhasse a subida e a descida do rio.

As moradoras entrevistadas por Pinheiro (2011) residem nas proximidades do Porto do Cacau Pirêra, local que é diretamente afetado pela subida e descida do rio Negro. Com a construção da ponte, o ambiente e as relações sociais foram e continuam sendo bastante modificadas. O rio foi substituído pela estrada, os barcos e as balsas pelos carros e caminhões. O espaço foi sendo ressignificado e, talvez, está deixando, já deixou ou deixará de ser lugar para as pessoas que tinham essa sensação. A travessia pelas águas do rio Negro terá outra cor, outras imagens, outros cheiros, enfim, outras sensações. Estas mudanças podem ocasionar a configuração do que era lugar em espaço e vice-versa.

Diferentemente do estudo de Pinheiro (2006), nas páginas dos noticiários os moradores do Iranduba aparecem como tendo preferência pela construção da ponte. O jornal A crítica estampou: "Sonho virou realidade - moradores lutaram por obra”. Na matéria, Antônio Maia, vice-presidente do Conselho de Cidadãos de Iranduba, que foi criado em 1999, é categórico ao dizer que essa realidade, que se concretizou com a inauguração da ponte, foi um sonho acalentado por mais de 30 anos pelos moradores do Iranduba e dos municípios vizinhos.

Em outubro de 2002, o mencionado conselho registrou no Cartório da Comarca de Iranduba o interesse pela construção da ponte. Maia afirma que esse registro é o DNA da ponte. Ainda em novembro de 2002, o conselho organizou a primeira audiência pública para a discussão da construção, relembra ele. Maia diz que de 2002 a 2007 foram realizadas oito audiências públicas; e em todas elas estavam presentes as lideranças dos municípios que foram atingidos diretamente: Iranduba, Novo Airão e Manacapuru. Ele aponta que:

A nossa maior briga foi para a melhoria do transporte aquaviário nesse trecho, que sempre foi inadequado, desqualificado e insuficiente. No início, a ideia da ponte sempre foi encarada como impossível, utópica, e era até tratada como piada pelas autoridades. Éramos chamados de doidos (A CRÍTICA, 2011, p. A10).

Novos Cadernos NAEA, v. 16, n. 1, Suplemento, p. 69-87, jun. 2013 
A exposição de Maia é rica em significados. Ao relembrar as lutas pela melhoria das condições da travessia, ele evidencia que a ponte era considerada algo estranho, surreal. E, por isso, os representantes do Conselho de Cidadãos de Iranduba nem sempre eram levados a sério.

Antes da construção da ponte, o transporte de passageiros, cargas e veículos automotores era feito majoritariamente por balsas administradas pela Sociedade de Navegação, Portos e Hidrovias do Estado do Amazonas (SNPH). Nas balsas, o transporte de passageiros pedestres era gratuito; e o de carros, ônibus e caminhões era cobrado. Existiam ainda pequenas embarcações que faziam a travessia de passageiros e de pequenas cargas. Ainda que houvesse certa variedade, as dificuldades na travessia do rio Negro eram inúmeras: quantidade insuficiente de balsas para suprir a necessidade da população; preço alto para transporte de carros e caminhões nas balsas; balsas e embarcações sucateadas; insegurança das pequenas embarcações, entre outras. A edificação da ponte sobre o rio Negro solucionou estes problemas, mas, por outro lado, também tem implicações negativas.

Para os trabalhadoresdasbalsas, ainauguraçãodapontee, consequentemente, a desativação do sistema de balsas no Porto de São Raimundo deixou marcas profundas em suas vidas e muitas saudades. Em outubro de 2011, último mês de funcionamento, o sistema estava funcionando com 6 balsas e 80 funcionários, os quais foram transferidos para o porto da Ceasa, situado no distrito industrial de Manaus. Em entrevista para o Jornal A crítica, o comandante Pedro da Silva diz que, após 19 anos de trabalho na travessia entre São Raimundo (Manaus) e Cacau Pirêra (Iranduba), sente-se com o coração apertado ao saber que as balsas deixam de funcionar com a inauguração da ponte. Em anos de dedicação, ele lembra que "nessas balsas eu conheci tanta gente, pessoas simples, autoridades do estado. Elas vão ficar gravadas na minha memória para o resto da minha vida. Terei que começar do zero na nova travessia" (A CRÍTICA, 2011, p. C15).

Outros trabalhadores atingidos diretamente pela inauguração da ponte foram os lancheiros, ou seja, aqueles que trabalhavam na travessia de passageiros em pequenas embarcações. Conforme informações do jornal A Crítica, a renda desses trabalhadores tem caído em um percentual que varia de $60 \%$ a $90 \%$. As lanchas que transitavam entre o Porto do Cacau Pirêra e o Porto de São Raimundo tiveram uma baixa bastante expressiva. O trabalhador João Dias, sócio da Associação de Taxi Marítimo de Frete (ATMF) diz que:

[...] nossa situação está a cada dia mais difícil. Estamos saindo com 6 a 7 passageiros por dia para o São Raimundo, quando o normal antes da ponte era 14, 20 passageiros. Alguns pararam e estão esperando o rio encher e melhorar o movimento, outros estão procurando outro meio de vida (CRÍTICA, 2011, p. A9).

Novos Cadernos NAEA, v. 16, n. 1, Suplemento Especial, p. 69-87, jun. 2013 
Os taxistas do Iranduba também reclamam que o faturamento caiu numa média de $40 \%$ até $60 \%$ após a abertura da ponte. Eles reivindicam a criação de um ponto de táxi nas proximidades da ponte, tanto no Cacau Pirêra, como na cidade de Manaus. O taxista Gilmar Oliveira esclarece que é necessário criar formas de bloquear a entrada dos taxistas da capital na praça do Iranduba, pois isto é uma concorrência desleal (A CRÍTICA, 2011, p. A9).

Já para os moradores da cidade de Manaus, que residem nas proximidades do porto do São Raimundo, a ponte trouxe mais tranquilidade, uma vez que a operação das balsas causava filas, sujeira, barulho e muita agitação de carros, motos, caminhões e de pedestres. Um casal de idosos que reside em frente ao Porto de São Raimundo agora comemora porque pode apreciar com mais placidez o rio Negro. Antes, a visão era entrecortada pelos carros, ônibus e caminhões. $\mathrm{Na}$ opinião do casal, a ponte trouxe mais qualidade de vida para os moradores do São Raimundo (A CRÍTICA, 2011, p. C15).

Como se vê, múltiplos são os olhares sobre a Ponte Rio Negro. As percepções são diferenciadas de acordo com os sujeitos e evidenciam algumas características, deixando de perceber tantas outras. Devemos recordar que cada indivíduo percebe o ambiente a partir do que é, ou seja, do seu corpo, de sua capacidade mental e sensorial motora, de sua cultura, de suas especificidades econômicas e sociais etc. Por isso, as percepções são diferentes.

Pensando o espaço e o tempo na Amazônia, Higuchi (2008) toma como referência as reflexões do matemático alemão Auguste Ferdinand Möbius, criador da fita de Möbius. A fita de Möbius é uma tira em formato circular, que possui uma superfície interna e outra externa, unidas de tal modo que é possível passar de uma superfície a outra sem cruzar a margem. A partir dessa figura é possível perceber, por similaridade, a conexidade e a continuidade do tempo e do espaço na vida humana.

Para Higuchi (2008), a fita de Möbius revela o comportamento da humanidade, uma vez que mesmo em tempos diferentes, anda-se sempre na mesma direção. $\mathrm{Na}$ fita concentra-se a relação entre espaço e tempo. Tempo este que é linear e cíclico em espiral. Partindo dessa analogia, a autora conclui que o homem precisa reavaliar urgentemente a forma arrogante com que lida com o ambiente. A relação homem e ambiente necessita ser revisitada. Referindo-se ao espaço amazônico, a autora expõe:

Preferimos as pontes majestosas a cruzar um rio de balsa contemplando a paisagem e se beneficiando do barulho das ondas produzidas com deslocamento da embarcação. Na ponte não há paisagem, pois esta cede lugar ao relógio. Essas formas de intervenção no ambiente nos levam para

Novos Cadernos NAEA, v. 16, n. 1, Suplemento, p. 69-87, jun. 2013 
lugares diferentes quando o tempo é nosso mestre de condução. Mexemos no tempo e no espaço sem constrangimento. Que tipo de consequência essa estratégia de nossa sociedade traz a nós humanos e ao ambiente? Que tipo de consequência essa estratégia tem quando tratamos de espaço na Amazônia? (HIGUCHI, 2008, p. 3-4).

Para os moradores da Amazônia e, mais especificamente, da cidade de Manaus, é evidente que a autora está se referindo à Ponte Rio Negro. A autora é instigante e nos leva a refletir acerca das opções que estão sendo feitas em nome de um modelo de desenvolvimento econômico. A justificativa para o projeto de construção da ponte, conforme o Relatório de Impactos Ambientais-RIMA (2007), é a consolidação e o desenvolvimento da Região Metropolitana de Manaus (RMM) e, por consequência, o alívio da pressão sobre o espaço urbano da capital.

O mesmo documento ressalta que os municípios envolvidos diretamente têm vários benefícios, dentre os quais são mencionados: fim do isolamento, facilidade de escoamento da produção, compartilhamento de serviços essenciais (saúde, educação, transporte etc.), criação de novos núcleos habitacionais, impulso econômico na área de turismo, geração de novos postos de trabalho, dentre outros.

Durante os três anos de construção da ponte sobre o rio Negro, a mesma foi assunto recorrente nos noticiários (jornal impresso, rádio e televisão). A ponte chamou a atenção não apenas pelo seu projeto arquitetônico, que foi mundialmente considerado como grandioso e ousado, mas também pelas modificações ambientais (espaciais e temporais), sociais, econômicas, políticas e culturais que trouxe para as localidades envolvidas.

As criações arquitetônicas afetam o ambiente, as pessoas que nele vivem, bem como o operários que as construíram. Uma construção arquitetônica demanda um conjunto de atividades complexas, que abarcam o ato de pensar, de tomar decisões, de adaptar, de inovar etc. O espaço construído pode aperfeiçoar e aprimorar as sensações e as percepções humanas. Gifford (2005) discorre sobre a importância do planejador social trabalhar em conjunto com o arquiteto para a construção do espaços físicos. Ele afirma que o projeto social é tão importante quanto o projeto formal (arquitetônico). E esclarece o caráter de distinção e de complementariedade de ambos os projetos para a construção do futuro.

O projeto formal favorece uma abordagem que pode ser descrita como de larga escala, corporativa, de alto custo, exclusiva, autoritária, levando a soluções de alta tecnologia, e preocupadas com o estilo, com o ornamento, com o cliente pagante e com um foco nacional ou internacional. Ao contrário, o projeto social favorece uma abordagem que pode ser descrita como de pequena escala, orientada para o humano, de baixo custo, inclusiva,

Novos Cadernos NAEA, v. 16, n. 1, Suplemento Especial, p. 69-87, jun. 2013 
democrática, tendendo a se apropriar da tecnologia, e preocupada com o significado e com o contexto, com o ocupante, tanto quanto com o cliente pagante, e com um foco local (GIFFORD, 2005, p.241).

A arquitetura produz espaços para a vida, que por meio das experiências vividas e do transcorrer do tempo, podem se tornar lugar para algumas pessoas. Por isso, a perspectiva social deve ser levada em consideração em qualquer projeto arquitetônico, desde a construção de uma pequena casa e, obviamente, nas grandes construções.

A construção da Ponte Rio Negro, como mencionado anteriormente, sempre foi um assunto muito polêmico. Durante várias décadas, a constatação de que a travessia do rio Negro era precária e carecia de melhorias fortaleceu, pouco a pouco, a ponte como solução para a viabilização de um transporte mais ágil. Conforme Pinheiro (2006), a travessia do rio Negro por meio de balsa começou a ser realizada em 1974. No início, era apenas uma única balsa, mas era suficiente para o quantitativo de pessoas e cargas. Durante os anos de 1980, os municípios, sobretudo Iranduba, receberam melhoramentos urbanos, gerando um crescimento populacional significativo e aumento da demanda para as balsas que faziam a travessia.

Não há duvidas de que os moradores dos municípios de Iranduba, Manacapuru, Novo Airão e da cidade de Manaus eram os mais afetados, pelas dificuldades de deslocamento de cargas e de passageiros entre o Porto do Cacau Pirêra e do São Raimundo. As dificuldades eram severas, mas será que a construção da Ponte era a melhor solução? O porto flutuante que era o anseio de alguns não poderia também ter sido uma possibilidade adequada à realidade? Estas são questões que se fundamentam em escolhas pautadas em perspectivas de mundo diferentes. De um lado uma visão mais ecológica e, de outro, uma opção que tem um apelo mercadológico bem maior.

À luz do pensamento de Gifford (2005) é possível questionarmos se o projeto para a construção da ponte buscou perceber as necessidades e compreender as percepções dos diferentes sujeitos envolvidos acerca do ambiente e das mudanças decorrentes do processo de construção. Tratou-se de um projeto democrático? Foi orientado para as necessidades humanas? São questões que extrapolam o objetivo do presente artigo, mas instigam a produção de outros estudos e reflexões acerca dos rumos tomados para o desenvolvimento urbano na Amazônia. 


\section{CONSIDERAÇÕES FINAIS}

O ambiente construído é marcado pela intervenção humana com propósitos previamente definidos, ou seja, o homem planeja a ação adequadamente para o alcance dos objetivos, levando em conta aspectos técnicos, econômicos, sociais, políticos, dentre outros. A construção de uma ponte é um exemplo claro de como o homem é capaz de intervir no ambiente de forma planejada.

A percepção do ambiente é fruto da interpretação humana. O homem percebe o mundo em sua volta através de suas capacidades mentais e sensóriomotoras e formula cognitivamente noções a este respeito. Estas noções são criadas e recriadas dinamicamente no movimento incessante da vida, visto que tanto o ambiente quanto o homem são passíveis de modificações contínuas.

A percepção ambiental consiste nas representações que advêm da relação homem e ambiente. É portanto, fruto de uma atividade intensa entre o homem e o mundo que o cerca. O homem apreende o objeto/o ambiente, analisa, entende, cria imagens e representa aquilo que consegue apreender. Esta apreensão é condicionada pela cognição e sensibilidade humana, com seus aspectos subjetivos e objetivos. Por isso, pode-se considerar que o ambiente é sempre uma interpretação possível de ser feita pelo sujeito em um dado momento.

A construção da Ponte Rio Negro provocou variadas percepções nos sujeitos. Como vimos, há percepções que se opunham à ponte e outras que a veem apenas como o início de um futuro próspero. Não há postura correta ou incorreta; são apenas posições divergentes, que enxergam ou deixam de enxergar determinados aspectos do ambiente.

Um ano após a inauguração da Ponte Rio Negro é possível observar várias mudanças de ambos os lados, tanto no Porto de São Raimundo, em Manaus, quanto no Porto do Cacau Pirêra, em Iranduba. No Porto de São Raimundo, o terminal hidroviário construído para organizar o sistema de balsas encontra-se obsoleto. O comércio existente em seu entorno também perdeu o grande fluxo, com a diminuição da circulação de pessoas. Em Iranduba, o porto abriga ainda alguns lancheiros e poucos comerciantes, que resistem e continuam no local. Nas proximidades do porto do Cacau Pirêra, onde havia uma área comercial estabelecida e muito movimentada, composta por feiras, mercadinhos e drogarias, agora amarga um período de desaquecimento das vendas.

A área portuária é o marco histórico do Cacau Pirêra. É o local onde se iniciou a colônia agrícola, que posteriormente deu origem à Vila do Cacau Pirêra em meados do século passado. É o referencial de origem dos moradores e o local das festas e da procissão à santa padroeira, Nossa Senhora Aparecida.

Novos Cadernos NAEA, v. 16, n. 1, Suplemento Especial, p. 69-87, jun. 2013 
O distrito vive e se organiza em torno do Porto. Com a Ponte Rio Negro esse ambiente ganhou uma outra dinâmica, que tem rebatimentos nos modos de vida e de trabalho dos moradores. Os moradores do Cacau Pirêra, sobretudo aqueles do entorno do porto, estão recriando a vida mediante às mudanças.

\section{REFERÊNCIAS}

BRAGA, E. Sonho realizado - Ponte é apenas o começo do futuro. A Crítica, Manaus, 24 out. 2011. Caderno Cidades, A11.

CAMPOS-DE-CARVALHO, M.I.; CAVALCANTE, S.; NÓBREGA, L.M.A. Ambiente. In: CAVALCANTE, S.; ELALI, G. (Orgs.). Temas básicos em psicologia ambiental. Petrópolis: Vozes, 2011.

CAVALCANTE, S.; NÓBREGA, L.M.A. Espaço e lugar. In: CAVALCANTE, S.; ELALI, G. (Orgs.). Temas básicos em psicologia ambiental. Petrópolis: Vozes, 2011.

FISCHER. G.-N. Psicologia Social do Ambiente. Lisboa: Instituto Piaget,1994. GIFFORD, R. O papel da psicologia ambiental na formação da política ambiental e na construção do futuro. Psicologia USP, São Paulo, v. 16, n.1-2, p. 237-247, 2005

GUNTHER, H. Affordance. In: CAVALCANTE, S.; ELALI, G. (Orgs.). Temas básicos em psicologia ambiental. Petrópolis: Vozes, 2011.

HIGUCHI, M.I.G. Tempo e espaço: Amazônia e globalização. In: SEMINÁRIO DE CIÊNCIAS DO AMBIENTE NA AMAZÔNIA, 2, 2008, Manaus, Anais... Manaus: UFAM, 2008.

HIGUCHI, M.I.G.; KUHNEN, A.; BOMFIM, Z.Á.C. Cognição ambiental. In: CAVALCANTE, S.; ELALI, G. (Orgs.). Temas básicos em psicologia ambiental. Petrópolis: Vozes, 2011.

KUHNEN, A. Percepção ambiental. In: CAVALCANTE, S.; ELALI, G. (Orgs.).

Temas básicos em psicologia ambiental. Petrópolis: Vozes, 2011.

MAIA, A. Sonho virou realidade - moradores lutaram por obra. A crítica, Manaus, 24 out. 2011. Caderno Cidades, A10.

MAIS TRANQUILIDADE para os moradores. A Crítica, Manaus, 24 out. 2011. Caderno Cidades, A10. 
PINHEIRO, H.A. Fronteiras da vida: o tradicional e o moderno no Cacau Pirêra/Iranduba (AM). 2006. Dissertação (Mestrado em Sociedade e Cultura na Amazônia) - Universidade Federal do Amazonas, Manaus, 2006.

PINHEIRO, H.A. Políticas públicas, urbanização e desenvolvimento na Amazônia: a construção da Ponte sobre o Rio Negro e as consequências para o Distrito Cacau Pirêra/Iranduba (AM). In: JORNADA INTERNACIONAL DE POLÍTICAS PÚBLICAS, 5, 2011, Recife. Anais... Recife, 2011.

REIGOTA, M. Meio ambiente e representação social. São Paulo: Cortez, 2010. Coleção Nova Coleção Questões da Nossa Época).

RENDA DE 'LANCHEIROS’ cai 90\% após a inauguração da ponte. A Crítica, Manaus, 24 out. 2011. Caderno Economia, A9.

SOUZA, F. Deputado afirma ser o pai da ponte. A Crítica, Manaus, 24 out. 2011. Caderno Cidades, A10.

TAXISTAS também reclamam. A Crítica, Manaus, 24 out. 2011. Caderno Economia, A9.

TRAVESSIA vai deixar saudades. A Crítica, Manaus, 24 out. 2011. Caderno Cidades, C15.

TUAN, Y-F. Espaço e lugar: a perspectiva da experiência. Tradução de Lívia de Oliveira. São Paulo: Difel, 1983.

UNIVERSIDADE FEDERAL DO AMAZONAS. Centro de Ciências do Ambiente. Relatório de Impactos Ambientais do empreendimento de travessia do rio Negro por ponte. Manaus, 2007. Relatório. 
